\title{
THE ROLE OF THE FETUS IN THE WATER EXCHANGE OF THE AMNIOTIC FLUID OF NORMAL AND HYDRAMNIOTIC PATIENTS *
}

\author{
By DONALD L. HUTCHINSON, MARY JANE GRAY, ALBERT A. PLENTL, \\ HERMOGENES ALVAREZ, ROBERTO CALDEYRO-BARCIA, \\ BRUNO KAPLAN AND JOHN LIND
}

\author{
(From the Department of Obstetrics and Gynecology, Columbia University College of Physicians \\ and Surgeons, and the Presbyterian Hospital, New York, N. Y.; the Seccion \\ Fisiologia Obstetrica de la Facultad de Medicina de Montevideo, Uruguay; \\ and the Wenner-Gren Cardiovascular Research Laboratory and the \\ Sodra Barnbord Sjukhuset, Stockholm, Sweden)
}

(Submitted for publication October 14, 1958; accepted March 5, 1959)

In a preceding report on exchange mechanisms in pregnant monkeys (1), evidence has been presented that the water exchange between the maternal organism and the products of gestation can be represented by a kinetic model composed of three major compartments, all of which exchange with each other. The three compartments are defined as: 1) the amniotic fluid, 2) the maternal, and 3) the fetal body water. It could be shown that the introduction of a hydrogen tracer into fetus or amniotic fluid results in retention curves of predictable shape and that transfer rates for water can be calculated with reasonable accuracy when the amniotic fluid was used as the primary compartment. It should therefore be possible to devise methods whereby the transfer rates for the human could be calculated and to study the role which the fetus plays in the exchange of water between the amniotic fluid and the mother.

For the calculation of transfer rates it is necessary to know the change in concentration of tracer as a function of time for each compartment. Continuous measurements on pregnant women are limited to the two accessible compartments: mother and amniotic fluid. In addition, a single sample of fetal or cord blood can be obtained at the time of delivery. Under these conditions there are two possible ways in which a time-activity curve for the fetal compartment can be calculated from available data. The first is based upon the

* This investigation was, in part, supported by a research grant from the National Institutes of Health, Department of Health, Education and Welfare; The Sloane Hospital Research Fund; and the Association for the Aid of Crippled Children. fact that, within the relatively brief period of time during which measurements are made, the total amount of tracer in all three compartments is constant. Ideally, the amount of tracer in the fetus should be equal to the difference between the amount of tracer injected and the sum of that in maternal and amniotic fluid compartments. The large difference in size between mother and the other compartments and the evident poor mixing in the maternal and fetal systems renders this approach too inaccurate for practical purposes.

The second possibility of deriving a time-activity curve for the fetus is somewhat more direct and takes advantage of the fact that at least one sample of fetal blood is available at termination of the experiment. The tracer concentration in the fetus follows a double exponential curve for which two points in addition to zero and infinity are necessary and sufficient for definition. If two tracers for hydrogen are injected into the primary compartment (amniotic fluid) at different times, analyses of cord blood for both tracers should give the two points from which the time-activity curve for the fetus can then be reconstructed.

The availability of deuterium and tritium made it possible to apply this method for the measurement of transfer rates in a series of normal pregnant women whose gestational ages ranged from 12 weeks to term. In two additional instances similar measurements were made on hydramniotic patients in an effort to describe further this abnormal state.

\section{THEORX}

Two points in addition to zero and infinity define the fetal tracer concentration curve. In theory any two 


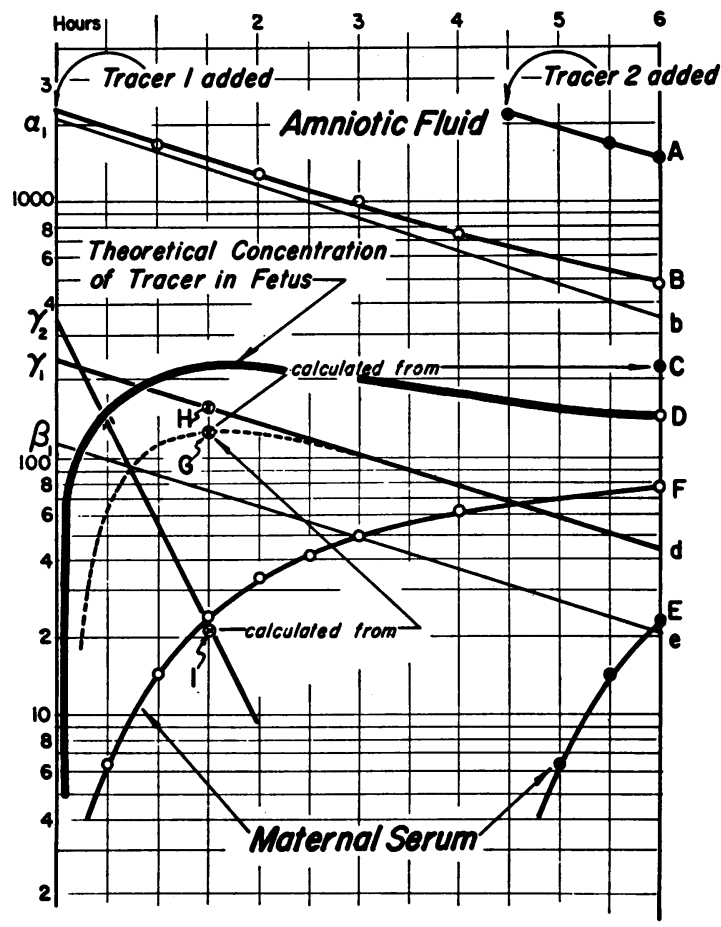

Fig. 1. Experimental Data Obtained on a Hydrodynamic Model (2) Illustrating the Method of Graphic Analysis, the Individual Steps of Which are DESCRIBED IN THE TEXT

The transfer rates and the volume of the three compartments had dimensions in the range anticipated for a term patient. The ordinate represents a scale common to both isotopes based on an estimated equilibrium value of 100 per cent.

points might serve the purpose but the practical application imposes certain limitations. Maximum accuracy would be expected if one of these points were to fall on the ascending, the other on the descending, portion of the curve whose general shape is known. If the fetal tracer concentration curve passes through a maximum, the concentration of the first tracer at any time beyond this maximum will be higher than the equilibrium value, while the concentration of the second tracer may be higher, equal to, or less than that of the first tracer. Under certain circumstances it is possible that the fetal tracer curve does not pass through a maximum, in which case the concentration of the first tracer will always be less than the equilibrium value yet higher than the second tracer. The relative position of these points and the equilibrium value crudely define the shape of the curve.

The manner in which the graphic analysis in all subsequent experiments was carried out is best illustrated by means of an example using a hydrodynamic model previously described (2). The first tracer was added to the "amniotic fluid" compartment at time zero. The concentration of this tracer was then measured in "maternal serum" and "amniotic fluid" every 30 minutes and the results plotted on an exact semilog scale (Figure 1 ). After four and one-half hours a second tracer was added to the "amniotic fluid" compartment and the experiment terminated at the end of the sixth hour. The tracer concentration for the "amniotic fluid" compartment at that time is given by Points A and B. A sample of fetal blood which had thus far been ignored was now analyzed for the two tracers and yielded Points $C$ and $D$. The two tracers in the maternal compartment are given by Points $E$ and F. Subtracting the equilibrium value of 100 per cent from each of the experimental points gives a straight line, the first exponential term, for the major portion of the curves. This holds for all three compartments alike. Line $b-\alpha_{1}$ is the first exponential term for the amniotic fluid and Line $e-\beta_{1}$ that for the maternal compartment. For the fetal curve this line must be reconstructed from Point D only. D minus 100 gives Point $d$ through which a line parallel to $b-\alpha_{1}$, the first exponential term, must pass. This line intersects $t=0$ at $\gamma_{1}$ which determines the first integration constant for the fetal compartment. The value for the second tracer can then be used to determine the second integration constant. $\mathrm{C}$ minus 100 gives a Point $\mathrm{G}$ which does not fall on Line $d-\gamma_{1}$ and this difference, the numerical values of $H$ minus $G$, determines Point $I$, through which a line representing the second exponential term must pass. Since the tracer concentration for the fetal compartment must be zero at $\mathrm{t}=0$, the second integration constant for this compartment is given by $\gamma_{2}=\gamma_{1}+100$. The line

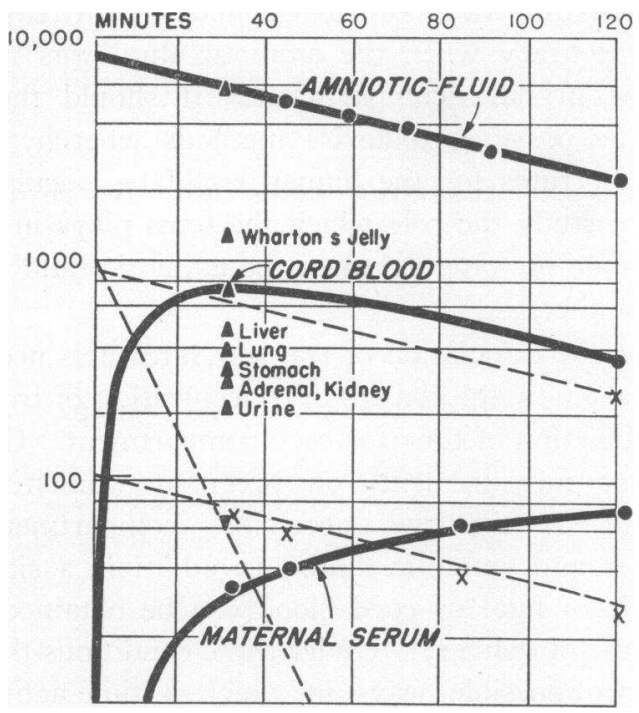

Fig. 2. The Time-Activity Curves for Amniotic Fluid, Cord Blood and Maternal Serum Measured on a Patient during the Twentieth Week of GesTATION

Deuterium oxide and tritium oxide were injected into the amniotic fluid 120 and 30 minutes before hysterotomy. Deuterium analyses are designated by circles; tritium analyses, by upright triangles. 


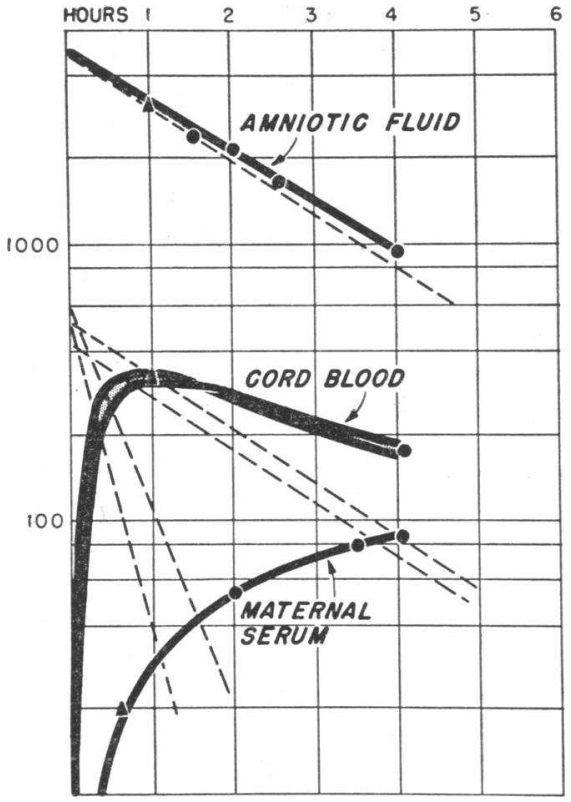

Fig. 3. Time-Activity Curves for Amniotic Fluid, Cord Blood and Maternal Serum Obtained on a Patient during the Twenty-Ninth WeEk of Gestation

The shaded area between the two curves for cord blood represents the limits compatible with the experimental data. Solid circles are deuterium and upright triangles tritium analyses. The dotted lines are the corresponding limits for the two exponential terms for cord blood.

$\gamma_{2}-I$ is the second exponential term for the fetal compartment and its slope the second exponential constant (for all three compartments). The remaining integration constants $\alpha_{2}$ and $\beta_{2}$ can be derived from a knowledge of the volume of each compartment and the value of the first integration constant $\alpha_{1}, \beta_{1}$ and $\gamma_{1}$. These constants are related to the transfer rates in the manner described previously (1).

\section{METHODS}

Reference to the analytic procedures for tritium and deuterium has been made in a preceding report (1). Only patients who had obstetrical indications for abdominal cesarean section or hysterotomy were used in this study. The general design of experiments on early and late pregnancies was similar but varied in the technique of the amniotomy and the period of observation over which samples were collected.

In term or near-term patients the amniotomy was done abdominally by a procedure described in detail elsewhere (3). At a predetermined time, ranging from one (normal) to two (hydramnios) hours after the injection of the second tracer, a cesarean section was performed and samples of cord or fetal heart blood obtained.

The four subjects at 12, 15, 15 and 20 weeks had vaginal hysterotomies in accordance with routine policy.
Abdominal amniotomy at such early stages of gestation was considered unnecessarily hazardous, hence the procedure was co-ordinated with the subsequent operation. The cervix was grasped with tenacula and, under local anesthesia, a transverse incision was made in the anterior fornix at the junction of cervical and vaginal mucosa. The vesico-cerival space was entered after division of the supra-vaginal septum and the bladder pushed upward by blunt dissection. A 16 gauge needle with stilette was then inserted into the substance of the cervix in the main axis of the fundus at the level of the internal os, the point of entry being just below the anterior peritoneal fold. Upon withdrawal of the stilette a multi-holed polyethylene catheter was introduced and the needle withdrawn over the catheter. The raw edges of muscosa were then approximated with a few interrupted chromic catgut sutures. The catheter, fitted with a two-way stopcock, was taped to the patient's thigh and the experiment was begun.

The general procedure was basically identical for all experiments. On the day before the contemplated operation a total body water determination was carried out by the deuterium oxide dilution method using 50 to 75 $\mathrm{ml}$. of the isotope containing 0.85 per cent sodium chloride. On the following morning an amniotomy was per-

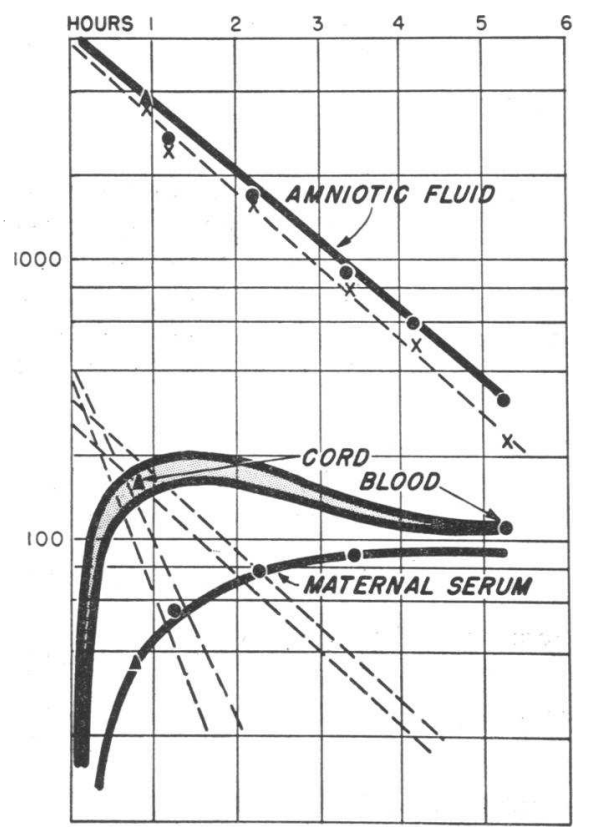

Fig. 4. Time-Activity Curves for Amniotic Fluid, Cord Blood and Maternal Serum Obtained on a Normal Term Patient Subjected to Elective Cesarean Section

Solid circles are deuterium; upright triangles, tritium analyses. The shaded area between the two curves for cord blood represents the limits compatible with experimental data. The dotted lines are the limits of exponential terms for çord blood. 


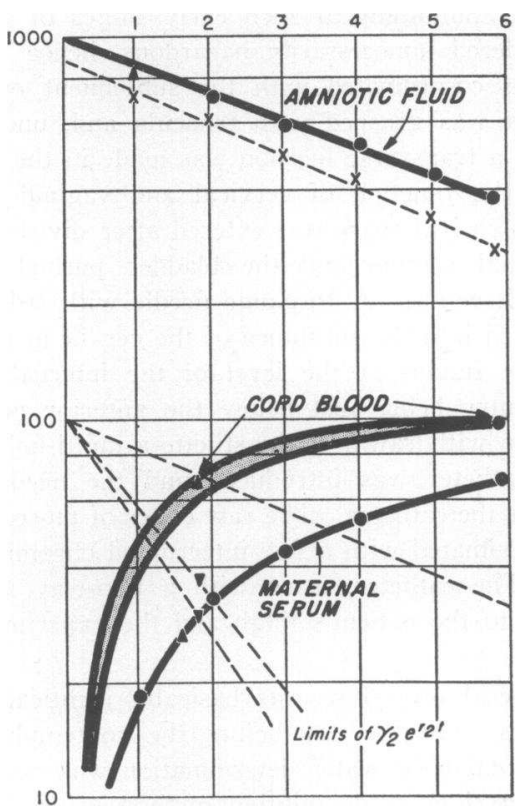

Fig. 5. Time-Activity Curves for Amniotic Fluid, Cord Blood and Maternal Serum Obtained on a PaTIENT With ACUTE Hydramnios

The shaded area between the two curves for cord blood represents the limits for transfer rates compatible with the experimental data. The dotted lines represent the limits for the two exponential terms.

formed either by the abdominal or vaginal route and control samples of amniotic fluid and maternal blood collected for determination of their deuterium content. A known and accurately measured amount of deuterium oxide was then injected into the amniotic cavity and thoroughly mixed by frequent withdrawal and reinjection of the amniotic fluid with a 20 or $50 \mathrm{ml}$. syringe. Simultaneously, a known amount of Congo red was introduced into the same compartment for the accurate determination of the fluid volume (4). The withdrawal and reinjection was continued throughout the remainder of the experimental period in order to insure proper mixing and sampling. Amniotic fluid and maternal blood were collected every 15 to 60 minutes. One mc. of tritiated water made isotonic with normal saline was then injected in like manner 20 minutes to two hours before cesarean section or hysterotomy. The interval over which the time-activity curves for the two tracers were determined depended upon the length of gestation and also upon the size of the primary compartment. During the early periods of gestation, hysterotomy was performed 20 to 30 minutes after the injection of tritium, while for the studies on hydramniotic patients at least two hours were allowed to elapse. Cesarean sections and hysterotomies were performed as quickly as possible and samples of cord or fetal heart blood were collected within less than one minute after rupture of the amniotic sac. In the four instances where the operation was performed as a therapeutic termination of pregnancy, samples of the more significant fetal tissues were collected for isotope analyses.

\section{RESULTS}

The results on four representative experiments are given in graphic form in Figures 2 through 5. The theoretic tracer concentration curve for the fetus was reconstructed in the manner described for the hydrodynamic model. The integration and exponential constants necessary for the calculations were obtained by graphic analysis of the data as described in the theoretic example

TABLE I

The calculated transfer rates for water during early pregnancies in ml. per hour*

\begin{tabular}{|c|c|c|c|c|c|}
\hline & & $\begin{array}{c}\text { No. } 2773 \\
\text { (12 weeks) }\end{array}$ & $\begin{array}{c}\text { No. } 2726 \\
\text { (15 weeks) }\end{array}$ & $\begin{array}{l}\text { No. } 2798 \\
\text { (15 weeks) }\end{array}$ & $\begin{array}{l}\text { No. } 2762 \\
(20 \text { weeks) }\end{array}$ \\
\hline Fetus to mother & $\rho_{1}$ & $\begin{array}{c}111 \\
(109-114)\end{array}$ & $\begin{array}{c}259 \\
(121-398)\end{array}$ & $\begin{array}{c}222 \\
(80-364)\end{array}$ & $\begin{array}{c}444 \\
(221-667)\end{array}$ \\
\hline Mother to fetus & $\rho_{2}$ & $\begin{array}{c}100 \\
(96-103)\end{array}$ & $\begin{array}{c}302 \\
(250-354)\end{array}$ & $\begin{array}{c}256 \\
(195-317)\end{array}$ & $\begin{array}{c}459 \\
(360-558)\end{array}$ \\
\hline Fetus to A.F. & $\rho_{3}$ & $\begin{array}{c}2.5 \\
(0-5)\end{array}$ & $\begin{array}{c}70 \\
(0-140)\end{array}$ & $\begin{array}{c}77 \\
(0-154)\end{array}$ & $\begin{array}{c}101 \\
(0-202)\end{array}$ \\
\hline A.F. to fetus & $\rho_{4}$ & $\begin{array}{c}11 \\
(10-12)\end{array}$ & $\begin{array}{c}37 \\
(30-44)\end{array}$ & $\begin{array}{c}38 \\
(29-47)\end{array}$ & $\begin{array}{c}78 \\
(64-92)\end{array}$ \\
\hline A.F. to mother & $\rho_{5}$ & $\begin{array}{c}64 \\
(63-65)\end{array}$ & $\begin{array}{c}107 \\
(85-129)\end{array}$ & $\begin{array}{c}97 \\
(73-121)\end{array}$ & $\begin{array}{c}103 \\
(68-139)\end{array}$ \\
\hline Mother to A.F. & $\rho_{6}$ & $\begin{array}{c}72 \\
(70-75)\end{array}$ & $\begin{array}{c}79 \\
(0-158)\end{array}$ & $\begin{array}{c}66 \\
(0-132)\end{array}$ & $\begin{array}{c}89 \\
(0-178)\end{array}$ \\
\hline
\end{tabular}

* The ranges shown represent the highest and lowest possible values compatible with the experimentally determined time-activity curves for the three compartments. 
TABLE II

The transfer rates for water in later stages of gestation and under conditions of hydramnios*

\begin{tabular}{|c|c|c|c|c|c|c|}
\hline & & 30 weeks & 38 weeks & 40 weeks & Hydramnios & Hydramnios \\
\hline Fetus to mother & $\rho_{1}$ & $\begin{array}{c}1,475 \\
(1,311-1,640)\end{array}$ & $\begin{array}{c}3,300 \\
(3,180-3,420)\end{array}$ & $\begin{array}{c}3,682 \\
(3,648-3,716)\end{array}$ & $\begin{array}{c}423 \\
(420-426)\end{array}$ & $\begin{array}{c}162 \\
(135-189)\end{array}$ \\
\hline Mother to fetus & $\rho_{2}$ & $\begin{array}{c}1,619 \\
(1,454-1,785)\end{array}$ & $\begin{array}{c}3,445 \\
(3,295-3,595)\end{array}$ & $\begin{array}{c}3,657 \\
(3,542-3,772)\end{array}$ & $\begin{array}{c}881 \\
(878-884)\end{array}$ & $\begin{array}{c}231 \\
(196-266)\end{array}$ \\
\hline Fetus to A.F. & $\rho_{3}$ & $\begin{array}{c}150 \\
(0-300)\end{array}$ & $\begin{array}{c}295 \\
(145-445)\end{array}$ & $\begin{array}{c}149 \\
(0-298)\end{array}$ & $\begin{array}{c}563 \\
(561-565)\end{array}$ & $\begin{array}{c}106 \\
(100-112)\end{array}$ \\
\hline A.F. to fetus & $\rho_{4}$ & $\begin{array}{c}164 \\
(157-171)\end{array}$ & $\begin{array}{c}285 \\
(270-300)\end{array}$ & $\begin{array}{c}165 \\
(150-174)\end{array}$ & $\begin{array}{c}99 \\
(97-101)\end{array}$ & $\begin{array}{c}36 \\
(35-39)\end{array}$ \\
\hline A.F. to mother & $\rho_{6}$ & $\begin{array}{c}160 \\
(153-167)\end{array}$ & $\begin{array}{c}200 \\
(180-220)\end{array}$ & $\begin{array}{c}247 \\
(235-259)\end{array}$ & $\begin{array}{c}527 \\
(524-530)\end{array}$ & $\begin{array}{c}456 \\
(444-468)\end{array}$ \\
\hline Mother to A.F. & $\rho_{6}$ & $\begin{array}{c}167 \\
(10-324)\end{array}$ & $\begin{array}{c}189 \\
(34-345)\end{array}$ & $\begin{array}{c}265 \\
(97-433)\end{array}$ & $\begin{array}{c}63 \\
(60-66)\end{array}$ & $\begin{array}{c}387 \\
(383-391)\end{array}$ \\
\hline
\end{tabular}

* The values in parentheses represent the maximal range compatible with measured time-activity curves for the three compartments.

and Figure 1. Table $I$ is a summary of the calculated ranges for transfer rates in early pregnancies and Table II represents the final data for later stages of gestation and hydramniotic patients. The analytic data for the tritium concentration in representative fetal tissues and body fluids are reproduced in Table III. On one set of fetal tissues mass spectrographic deuterium and tritium analyses were carried out in an effort to determine the degree of equilibration which had occurred as a function of time. These findings are reproduced in Table IV. Tritium analyses of specific sections of cord from normal and hydramniotic patients are summarized in Table $\mathrm{V}$.

TABLE III

Relative tritium concentration in various fetal tissues, urine and placenta 19 to 30 minutes after injection of a known amount of tritium into the amniotic fluid*

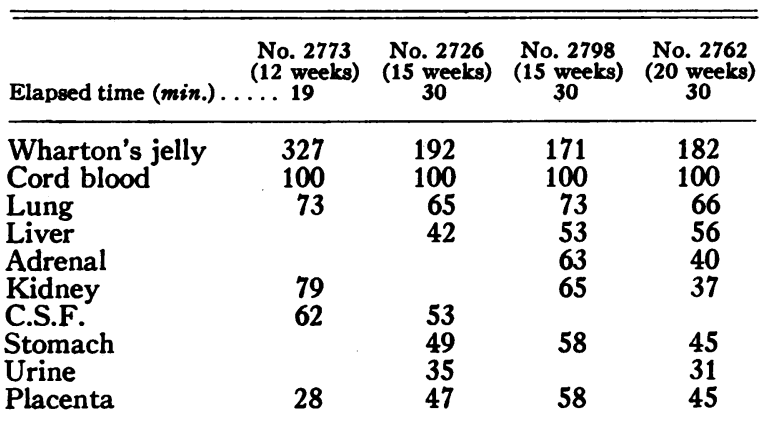

* The values were obtained by combustion of wet tissue and the specific activity is related to cord blood, arbitrarily set at 100 per cent.

\section{DISCUSSION}

In addition to the main assumptions upon which all tracer experiments are based, the system here considered must be in a steady state and the two tracers must perform in identical manner at least over the brief period of observation. Because of the wide differences in the mass of hydrogen, deuterium and tritium, an isotope effect could conceivably occur. In order to demonstrate that the assumption of identical performance is valid, a series of experiments was carried out in which first deuterium and then tritium was injected into the amniotic fluid of pregnant patients at term. Their disappearance from the amniotic fluid and appearance in the

TABLE IV

Hydrogen isotope concentrations in fetal tissues obtained on Patient 2762 (Figure 2, Table III)*

\begin{tabular}{lrr}
\hline & Tritium & Deuterium \\
\hline Wharton's jelly & 182 & \\
Cord blood & 100 & 100 \\
Lung & 66 & 72 \\
Liver & 56 & 78 \\
Adrenal & 40 & 60 \\
Kidney & 37 & 49 \\
Stomach & 45 & 50 \\
Placenta & 45 & 48 \\
Urine & 31 & 70 \\
\end{tabular}

* For purposes of comparison the concentration of each isotope in cord blood was arbitrarily set at 100 . The tritium values were obtained 30 minutes, the deuterium values 120 minutes, after the injection of the isotope. 
TABLE V

Comparison of the tritium concentration in cord blood and Wharton's jelly one to two hours after injection of a known amount of tritium into the amniotic sac *

\begin{tabular}{lrrr}
\hline \hline & $\begin{array}{c}\text { Cord } \\
\text { serum }\end{array}$ & $\begin{array}{c}\text { Cord } \\
\text { near } \\
\text { fetus }\end{array}$ & $\begin{array}{c}\text { Cord } \\
\text { near } \\
\text { placenta }\end{array}$ \\
\hline Normal (30 weeks) & 330 & 1,095 & 711 \\
Normal (term) & 160 & 1,138 & 875 \\
Hydramniost (term) & 26 & 166 & 139 \\
Hydramniost (term) & 68 & 248 & 194
\end{tabular}

* All values are referred to an equilibrium value of 100 per cent.

$\dagger$ Normal baby.

$\ddagger$ Congenitally abnormal baby.

maternal circulation was measured. It could be shown that in the same patient the two tracers give identical time-activity curves. The results of one such experiment are reproduced in Figure 6 , which shows how the two tracer curves "chase" each other, the second (tritium) reproducing a pattern identical with the first (deuterium), temporally displaced. An isotope effect, if it occurs at all, is therefore negligible and is not expected to have an appreciable influence upon the final results.

Qualitatively, the shape of the retention and appearance curves for the three compartments is predictable. For the calculation of transfer rates,

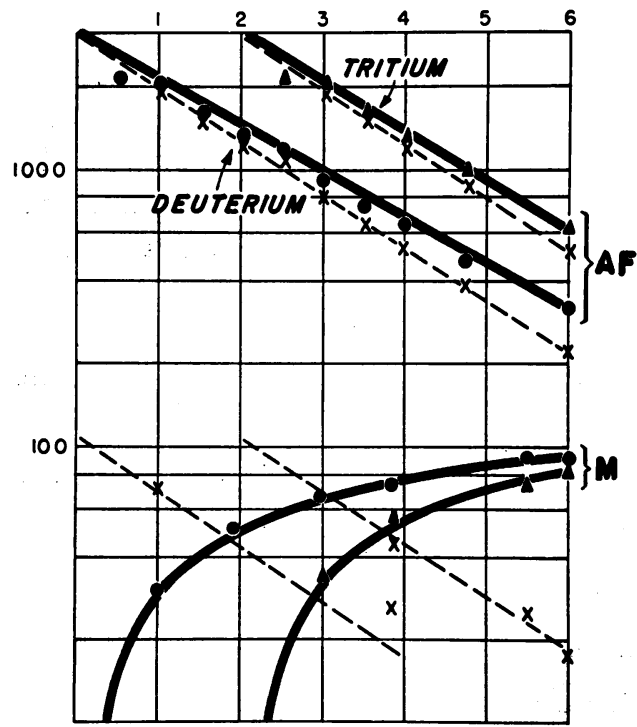

Fig. 6. Deuterium and Tritium Concentration in Amniotic Fluid (A.F.) and Mother (M) AS A FuncTION OF TIME IN Hours

Both tracers were injected into the amniotic sac at the time indicated. they must be determined with the highest possible accuracy and only the most reliable sections of these curves can be considered. The time interval from injection of the two tracers to the termination of the experiment must be so chosen that the two points for the fetal curve fall within a specific range: the first tracer on the descending and the second tracer on the ascending portion of the curve. In the experiments carried out during early pregnancies only a very rough estimate could be made on the basis of models and previous experience on term patients. Slightly more reliable curves than those shown in Figure 2 could have been obtained had the experiments been carried out over a longer period of time and the exposure to tritium shortened. Tritium exposures of less than 20 minutes would give experimental points on the rising portion of the curve and thus, at least in theory, lead to a more accurate calculation of the second exponential constant. Unfortunately, such brief intervals probably would not permit an adequate distribution of the tracer within this compartment and the tritium concentration then would not be comparable to the deuterium concentration in the same sample of cord blood.

The functional anatomic complexity of the maternal organism leads to unreliable tracer curves for this compartment which cannot be used for the calculation of transfer rates. Attempts to do so in experiments carried out on rhesus monkeys (1) led to inconsistent results. Fortunately, it is not necessary to use the maternal curves for this purpose since all the essential information can be obtained from the values of the amniotic fluid and fetal compartment.

Satisfactory mixing in the amniotic fluid compartment is evident from its consistent retention curves. Whenever the amniotic fluid volume was large in comparison to the size of the fetus (e.g., in early pregnancies and under conditions of hydramnios) the first exponential constant could be fixed within very narrow limits. Only an exceedingly small error was therefore carried over to the second exponential constant which, in turn, depends upon the accuracy of the deuterium analysis in cord blood. The analytic error in these determinations can be brought to negligible proportions and the total error depends mainly upon the degree of mixing in the fetal compartment. 
The analyses of tissue samples made it possible to estimate the extent of distribution which had taken place since the injection of both tracers. The analytic data of Table III were obtained by combustion of wet tissues rather than lyophilization; hence, the specific activity of the hydrogen gas produced requires correction. In the combustion of solid fetal tissues unlabeled hydrogen is introduced. This dilution can be estimated as about 20 to 25 per cent if it is assumed that the sample consisted of not more than 40 per cent solids. The actual isotope concentration is, therefore, considerably higher than would appear from the data of Table III and if such corrections were made, the data would indicate a nearly complete equilibration within the brief period of 20 to 30 minutes. With or without this correction, the highest specific activity was found in lung and there was a relatively even distribution in the other organs. The isotope concentration in placental tissue was invariably low while Wharton's jelly had a relative specific activity which exceeded that of cord blood several times. Comparing the distribution of tritium with the distribution of deuterium in the same subject and the same samples of hydrogen gas obtained by combustion (Table IV) it is evident that there was only a very slight, relative increase of the tracer concentration over an additional 120 minutes of exposure. The only exception appears to be the sharp rise of isotope content in fetal urine (from 31 to 70 per cent) which represents definite evidence that the fetal kidneys are active, even at 12 weeks of gestation.

As pregnancy progresses the role of the fetus in the various exchange mechanisms might possibly change. At 12 weeks gestation the exchange between amiotic fluid and fetus is small compared to the direct exchange between amniotic fluid and mother. At term 40 per cent of the transfer from the amniotic fluid to the maternal system takes place through the intermedium of the fetus. This is not at variance with indirect evidence previously presented (5) that at term at least 25 per cent of the water transfer from the amniotic fluid to mother takes place through the fetus. The reported transfer rates are given in terms of a range compatible with the measured experimental data: Even the lowest possible values for the transfer of water from mother to

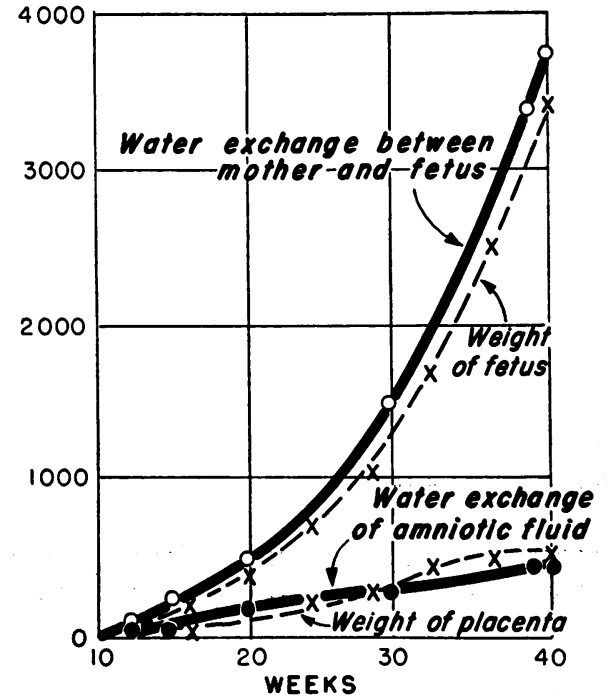

Fig. 7. The Relation of Water Exchange in Ml. per Hour to Age of Gestation

The values are related to reported average values for fetal and placental weight in grams.

amniotic fluid constitute an appreciable proportion of the total exchange and hence this pathway exists throughout pregnancy.

The transport of water from mother to fetus, presumably via the placenta, has been investigated by Hellman and co-workers (6), who found a progressive rise with age of gestation followed by a sharp decline at term. This was attributed to aging of the placenta, a phenomenon correlated with morphologic (7) and biochemical studies (8). In the present investigations this decline in water transmission near term could not be confirmed and the measurements point to a constant rise in this exchange rate until delivery as shown in Figure 7. The amount of water exchanged per hour increases from about $100 \mathrm{ml}$. per hour during the twelfth week to $3,600 \mathrm{ml}$. per hour at term. A similar, consistent rise in the total water exchange of the amniotic fluid has been observed which, incidentally, appears to be proportional to the increase in placental weight. Under the pathologic condition of hydramnios the water exchange between the maternal and fetal organism is grossly impaired. As shown in Table II this exchange rate in one of the patients was about one to eight, in the other less than one to 20 that of normal pregnant women. The difference in these transfer rates is beyond the 
TABLE VI

The total transfer of water, sodium and potassium from amniotic fluid to mother and fetus in normal and hydramniotic patients*

\begin{tabular}{clll}
\hline \hline & \multicolumn{3}{c}{ Transfer rates $(m E q . / h r$.) } \\
\cline { 2 - 4 } A. F. volume & $\mathrm{D}, \mathrm{O}$ & $\mathrm{Na}$ & $\mathrm{K}$ \\
\hline $\begin{array}{c}\text { Less than 2,000 ml. } \\
\text { (range, 385-1,420) }\end{array}$ & 26,100 & 12.0 & 0.5 \\
$\begin{array}{c}\text { More than 2,000 ml. } \\
\text { (range, 2,000-6,000) }\end{array}$ & 27,300 & 12.3 & 0.6 \\
\hline
\end{tabular}

* There is no statistically significant difference between the two groups of patients.

experimental error and the relatively narrow limits for these measurements render the data very reliable.

The transfer from amniotic fluid directly to the mother $\left(\rho_{5}\right)$ is proportionately increased, thus superficially resembling the situation prevailing during earlier periods of gestation. The total amount of water leaving the amniotic fluid per unit of time $\left(\rho_{4}\right.$ plus $\left.\rho_{5}\right)$ for both groups is not appreciably different for the two groups. It amounts to 492 and $626 \mathrm{ml}$. per hour for the two hydramniotic patients and 412 and $490 \mathrm{ml}$. per hour for the two normal term patients. This confirms the earlier observations of Hutchinson, Hunter, Neslen and Plentl (9) that the total water and electrolyte transfer is independent of the volume of the amniotic fluid. For comparison, a summary of the data reported by these authors is given in Table VI. In hydramniotic patients, therefore, the amount of water leaving the amniotic fluid compartment is about the same or only slightly increased over that measured in normal patients. Thus, the "removal" of water is certainly not impaired; if anything, it is increased. The two groups, however, differ in one important aspect: In the normal patient most of this transfer is accomplished through the intermedium of the fetus, while under conditions of hydramnios a bypass of some sort seems to exist. This may be a simple diffusion phenomenon directly transmitting the water from the amniotic fluid to the maternal organism or more likely related to some change or lesion of the feto-placental circulatory system. That some physiologic, functional change has occurred in this system is shown by the depressed exchange of water between mother and fetus (Figure 8).
In the experiments on term pregnancies samples of fetal tissue were not available, but sections of placentae and cord were examined for their tritium content. The tracer concentration in placental tissue was less than that of cord blood and did not show any appreciable variations in samples taken from different areas of this organ. Wharton's jelly, on the other hand, showed a consistent gradient. The specific activity of samples taken near the baby was invariably higher than that of cord samples near the placental insertion. The difference was appreciable, consistent, and beyond the experimental error of the method. The significance of this gradient is not clear at the present time but may well be related to a specific transfer mechanism of water through the cord.

With certain reservations these data might be used for tentative conclusions regarding the sites of exchange. The strikingly high concentration of tritium in Wharton's jelly makes it very likely that the major part, perhaps all, of the water exchange of the amniotic fluid takes place through this organ. A direct transfer through the membranes and decidua to the maternal system cannot be ruled out and the data obtained in this investigation cannot be used to distinguish between these possibilities. The low specific activity of placental tissue when compared to cord blood does not permit similar conclusions to be drawn since the transmission of water across the placenta is a rapid process and the appearance of the tracer a transitory phenomenon. It is to be expected that the specific activity of placental tissue be less than cord blood yet more than that of maternal serum.

The site and mechanisms of water exchange between amniotic fluid and fetus are not entirely clear. In these experiments the amniotic fluid was the primary compartment and its tracer concentration was appreciably higher than that of the other two compartments at any time during the experimental period. Stomach and lung, if contaminated with amniotic fluid, should contain very appreciable amounts of tritium in excess of that transmitted through the fetal blood stream. Although there are considerable variations from one specimen to another, the findings were quite consistent for the tissues obtained during the early periods of gestation. None of them, except Wharton's jelly, had an isotope concentration greater than that of cord blood. Swallowing and aspira- 
12 MeEks
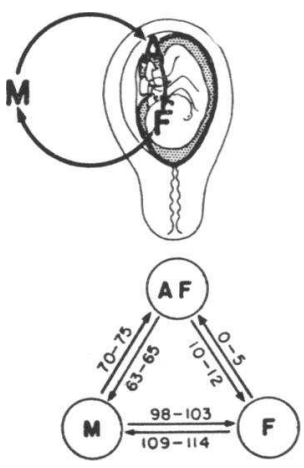

30 MEEKS
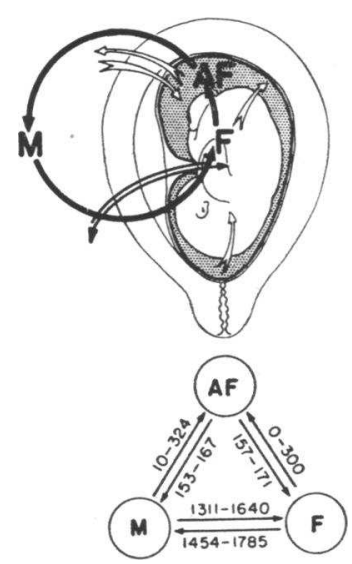

MORMaL
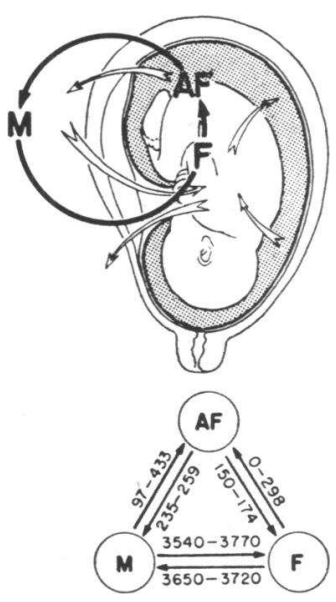

HYORAMNios
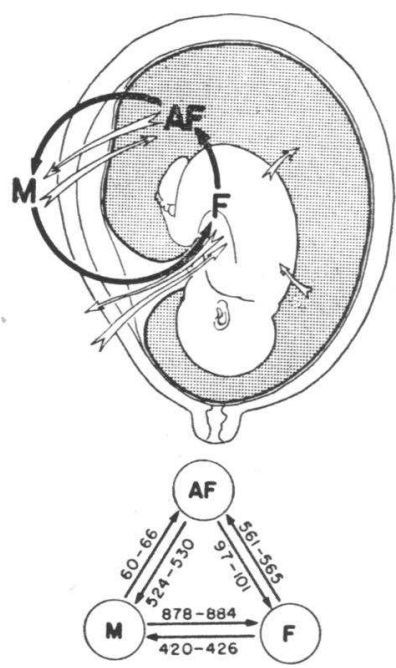

Fig. 8. Schematic Presentation of the Water Exchange between Mother (M), Fetus (F) and Amniotic Fluid (A.F.) in Normal and Pathologic Pregnancies

The arrows in the lower portion of the diagram indicate the direction; the values assigned to them, the hourly transfer in milliliters. The heavy circles to the left of each diagram designate the direction of the net transfer, i.e., the "circulation" of the water.

tion may well account for a small part of the transfer between amniotic fluid and fetus but it is likely that most of the water passes through the cord.

\section{SUM MARY}

The quantity of water transferred between amniotic fluid, fetus and mother has been determined by means of isotopic tracers. Because of the inaccessibility of the human fetus, time-activity curves for the fetal compartment cannot be determined directly and a method was devised and tested whereby this curve could be reconstructed from the amniotic fluid retention curve and a single sample of cord blood obtained at the time of delivery.

2. The method consists of injecting first a known amount of deuterium oxide followed by tritium oxide into the amniotic sac of pregnant women. Fifteen to 60 minutes after the injection of the second tracer cesarean sections or hysterotomies were performed. The concentration of the two tracers in cord blood, in addition to the initial and final, theoretic equilibrium value, define the fetal curve. The mathematical treatment of the data made it possible to calculate the six transfer rates between the three hypothetical compartments.

3. Seven such experiments were carried out on normal pregnant women whose gestational ages ranged from 12 weeks to term. In the early stages of pregnancy the exchange of water between amniotic fluid and mother is of about the same magnitude as the exchange between mother and fetus. As pregnancy progresses the role of the fetus in this transfer becomes more significant and at term about 40 per cent of the water transfer from amniotic fluid to mother is accomplished through the intermedium of the fetus. Throughout the entire period of gestation there exists a direct pathway of exchange between amniotic fluid and maternal organism. The exchange of water between mother and fetus rises progressively with fetal weight and amounts to $3.5 \mathrm{~L}$. per hour at term.

4. Identical studies carried out on hydramniotic patients at term led to the conclusion that this pathologic state is associated with a pronounced decline in the exchange rate between mother and fetus. Most of the water of the amniotic fluid now originates from the fetal system and most of its removal is accomplished by a direct transfer to the maternal compartment. 
5. Deuterium and tritium analyses of organs obtained from four nonviable fetuses indicated an almost complete equilibration within a period of 20 to 30 minutes. Thirty and 120 minutes after the injection of the tracers into the amniotic fluid, fetal urine had 30 and 70 per cent, respectively, of the cord blood levels. Wharton's jelly had an isotope concentration several times higher than that of cord blood, but lower than that of the amniotic fluid at the time of termination. This consistent finding was thought to indicate that most, perhaps all, of the water transfer between amniotic fluid and fetus takes place through the cord.

\section{REFERENCES}

1. Friedman, E. A., Gray, M. J., Hutchinson, D. L., and Plentl, A. A. The role of the monkey fetus in the exchange of the water and sodium of the amniotic fluid. J. clin. Invest. 1959, 38, 961.

2. Plentl, A. A., and Gray, M. J. Hydrodynamic model of a 3-compartment catenary system with exchanging end compartments. Proc. Soc. exp. Biol. (N. Y.) $1954,87,595$.
3. Plentl, A. A., and Gray, M. J. Physiology of the amniotic fluid and the management of hydramnios. Surg. Clin. N. Amer. 1957, April, 405.

4. Neslen, E. D., Hutchinson, D. L., Hallet, R. L., and Plentl, A. A. Dilution methods for determination of amniotic fluid volume. Obstet. and Gynec. 1954, 3, 598.

5. Gray, M. J., Neslen, E. D., and Plentl, A. A. Estimation of water transfer from amniotic fluid to fetus. Proc. Soc. exp. Biol. (N. Y.) 1956, 92, 463.

6. Hellman, L. M., Flexner, L. B., Wilde, W. S., Vosburgh, G. J., and Proctor, N. K. The permeability of the human placenta to water and the supply of water to the human fetus as determined with deuterium oxide. Amer. J. Obstet. Gynec. 1948, 56, 861.

7. Flexner, L. B., Cowie, D. B., Hellman, L. M., Wilde, W. S., and Vosburgh, G. J. The permeability of the human placenta to sodium in normal and abnormal pregnancies and the supply of sodium to the human fetus as determined with radioactive sodium. Amer. J. Obstet. Gynec. 1948, 55, 469.

8. Villee, C. A. The metabolism of the human placenta in vitro. J. biol. Chem. 1953, 205, 113.

9. Hutchinson, D. L., Hunter, C. B., Neslen, E. D., and Plentl, A. A. The exchange of water and electrolytes in the mechanism of amniotic fluid formation and the relationship to hydramnios. Surg. Gynec. Obstet. 1955, 100, 391. 